\title{
Cost-saving Minimal Incision Endoscopic-assisted Cubital Tunnel Release Using Simple Surgical Instruments: Case Series
}

\author{
Woraphon Jaroenporn ${ }^{1}$, Pradit Predeeprompan ${ }^{2}$, Jaruwat Vechasilp ${ }^{2}$, Torpon Vathana ${ }^{3}$, Roongsak \\ Limthongthang ${ }^{3}$ \\ 1. Hand and Microsurgery, Orthopaedic Surgery, Police General Hospital, Bangkok, THA 2. Orthopaedics, Police \\ General Hospital, Bangkok, THA 3. Orthopaedic Surgery, Siriraj Hospital, Bangkok, THA
}

Corresponding author: Woraphon Jaroenporn, dr.woraphon@yahoo.com

\begin{abstract}
Cubital tunnel syndrome (CuTS) is a well-recognized compressive neuropathy worldwide. With technological advancement, endoscopy is introduced to facilitate the procedure. However, there are concerns about the excessive cost that comes with special instruments. This article aims to provide the results of the costsaving endoscopic-assisted cubital tunnel release surgical technique that uses the normally available operating instruments.

A retrospective review was performed of the nine patients that were diagnosed with CuTS and underwent minimal incision endoscopic-assisted cubital tunnel release in Police General Hospital. Patients were followed up to sixth month postoperation. The modified McGowan classification was used to determine the severity of symptoms. Surgical outcomes were evaluated by the modified Bishop classification, visual analog score (VAS), and patients' satisfaction. Other factors investigated were scar pain and peri-incisional numbness and hematomas.
\end{abstract}

The incisions were measured as 7-9 mm. All patients reported having a pain score of 1 on the third day. Seven of nine patients were able to return to work one day after surgery. Modified Bishop score showed five excellence, three good, and one fair after two weeks. There was no surgical-related complication found. All patients noted the excellence satisfaction of the procedure.

The minimal incision endoscopic-assisted cubital tunnel release has shown favorable outcomes with the cost-saving of simple instruments. However, a large prospective trial may be needed for further study.

Received 10/07/2019

Review began 10/11/2019 Review ended 10/14/2019 Published 10/15/2019

\section{Copyright 2019}

Jaroenporn et al. This is an open access article distributed under the terms of the Creative Commons Attribution License CC-BY 3.0., which permits unrestricted use, distribution, and reproduction in any medium, provided the original author and source are credited.
Categories: Plastic Surgery, Neurosurgery, Orthopedics

Keywords: decompression, compressive neuropathy, cubital tunnel syndrome, minimal invasive, endoscopic, in situ decompression, cost effective

\section{Introduction}

Cubital tunnel syndrome (CuTS) is the second most common peripheral neuropathy [1]. There are three concepts in surgical approaches for the treatment of CuTS, including in situ decompression, transposition, and epicondylectomy [2]. Recently, simple decompression has steadily gained support for its better costeffectiveness and lower complication rate [3-4]. There are many variations in the open in situ cubital tunnel release technique from the classical to the minimal incision. The classical incision normally uses an 8-10 $\mathrm{cm}$ length of incision, which allows wide exposure but endangers the median antebrachial cutaneous nerve (MABC) as well as causes postoperative pain and increases healing time [2,5]. Various minimal incision techniques were proposed using the mobility of the soft tissue around the elbow to shorten the recovery time and reduce scar tenderness and iatrogenic injury to MABC [6]. The cadaveric studies show that the compressive structures spanning from an average of $8.2 \mathrm{~cm}$. proximal to $6.4 \mathrm{~cm}$ distal from the medial epicondyle [7], Josep Said et al. stated that a 4-cm open incision is needed to allow the visualization of $9 \mathrm{~cm}$ [8]. There are many studies that support that endoscopic cubital tunnel decompression has a smaller incision, greater field of view, better short-term outcome, and fewer complications [9]. Many authors have used various special instruments that raise concern on excessive expense and cost-effectiveness [5]. To our knowledge, few studies used basic operating instruments, with a $1.5-2 \mathrm{~cm}$ incision, which is not too different from minimal incision open cubital tunnel release. This retrospective case series was performed to propose the results of the novel procedure of the $7-9 \mathrm{~mm}$ incision, which is easily replicable and cost-saving.

\section{Case Presentation}

\section{Materials and methods}

A retrospective review was performed to identify patients who were diagnosed with CuTS between August 2017 and August 2019 and underwent minimal incision endoscopic-assisted cubital tunnel release 


\section{Cureus}

performed by a single surgeon. Nine patients were identified. The severity of the symptoms was classified with the modified McGowan classification (Table 1) [10]. Radiographs of all nine elbows showed no deformity or significant osteoarthritis. In the modified Bishop classification (Table 2) [11], the visual analog score, patients' satisfaction were used to evaluate the patients in the first 10 days postoperation via telephone by the same resident who was not involved in the study. The patients were appointed to the clinic in the second, fourth, and sixth weeks and then in the third and sixth months with the same evaluation protocol.

\begin{tabular}{|l|l|}
\hline Grade & Description \\
\hline 1 & Purely subjective symptoms causing dysfunction in daily activities \\
\hline $2 \mathrm{~A}$ & Muscle weakness with or without subjective symptoms, without detectable atrophy \\
$2 \mathrm{~B}$ & Muscle weakness with or without subjective symptoms, with detectable atrophy \\
3 & Disabling weakness, marked intrinsic atrophy, and profound sensory disturbances
\end{tabular}

TABLE 1: Modified McGowan score

Items

Residual symptoms

None

Little/Intermitted

Moderate

Severe

Subjective improvement

Better

Unchanged

Worse

Ability to work

Working in old job

Changed job due to complains

Incapable of working

Muscle strength

Better

Unchanged

Evaluation

Excellent

Good

TABLE 2: Modified Bishop score

\section{Surgical technique}




\section{Cureus}

The operation is performed under general anesthesia with a pneumatic tourniquet. The affected arm is positioned on an arm board set perpendicular to the bed. The sterile technique is performing in the standard fashion. The medial epicondyle, olecranon, along with the ulnar nerve, are identified and marked. The longitudinal, 7 to 9-mm long incision is made on the skin overlying the ulnar nerve. The Senn retractor is used to gain better visualization (Figure 1). Metzenbaum scissors are used for dissecting soft tissue while taking care not to injure the MABC. After incising the aponeurosis and fascia compressing the ulnar nerve, the small Langenbeck retractor is introduced along the length of the incision and then rotated $90^{\circ}$ in order to elevate the soft tissue above the ulnar nerve. The $2.5 \mathrm{~mm}, 30^{\circ}$ endoscope is now introduced into the field (Figure 2). After the ulnar nerve is localized, the curved short blade Metzenbaum is now used to cautiously dissect the compressing soft tissue overlying the ulnar nerve under a clear endoscopic view (Figure 3). Nine $\mathrm{cm}$. proximal, as well as distal, to the medial epicondyle of the ulnar nerve is decompressed with the same technique. Care is taken to avoid injury to the branches and vessels of the ulnar nerve. After satisfaction, meticulous hemostasis is obtained. The surgical wound is closed with a single, absorbable, 5-0 monofilament suture. The patients are instructed to start motion immediately after the operation.

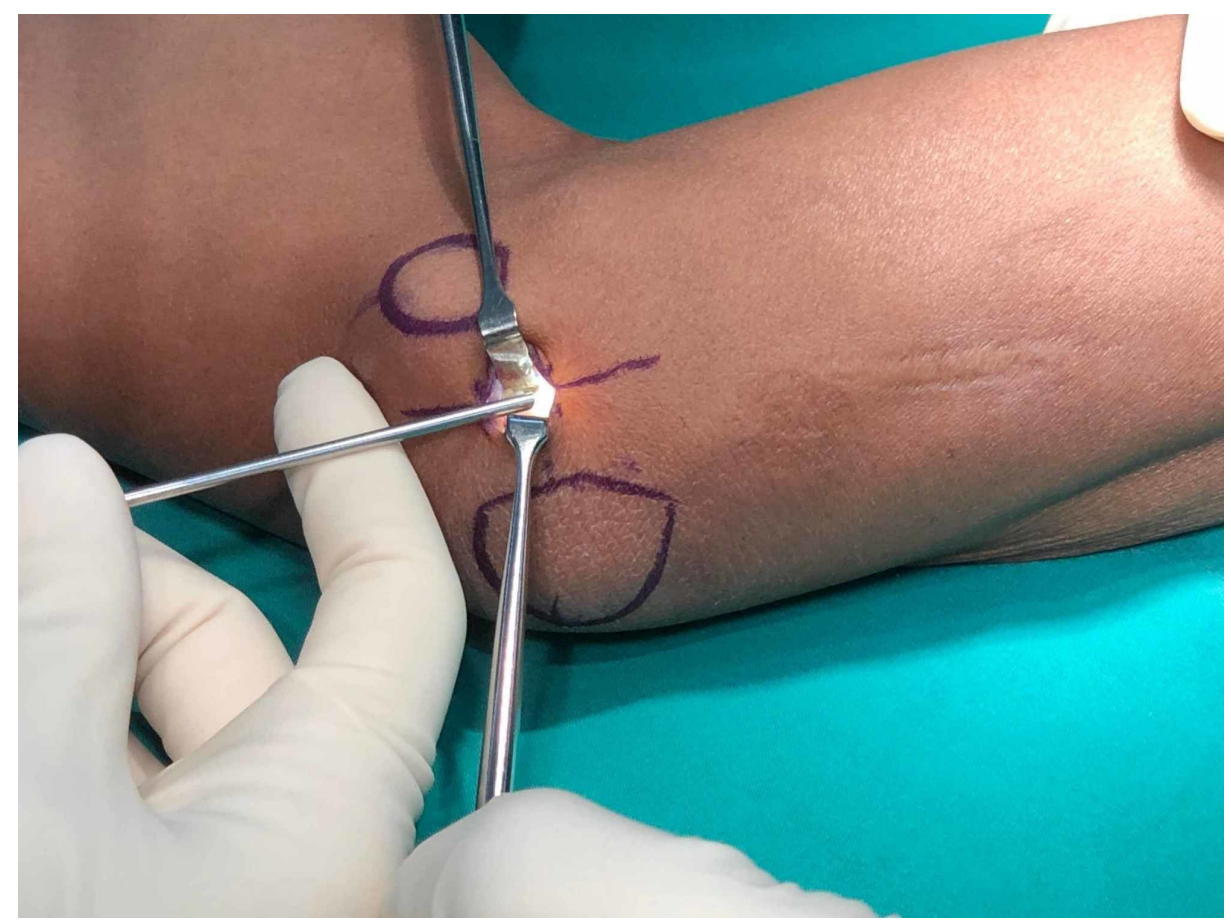

FIGURE 1: The ulnar nerve is identified with a $7-9 \mathrm{~mm}$ incision using Senn retractors to facilitate the mobility of the soft tissue around the elbow 


\section{Cureus}

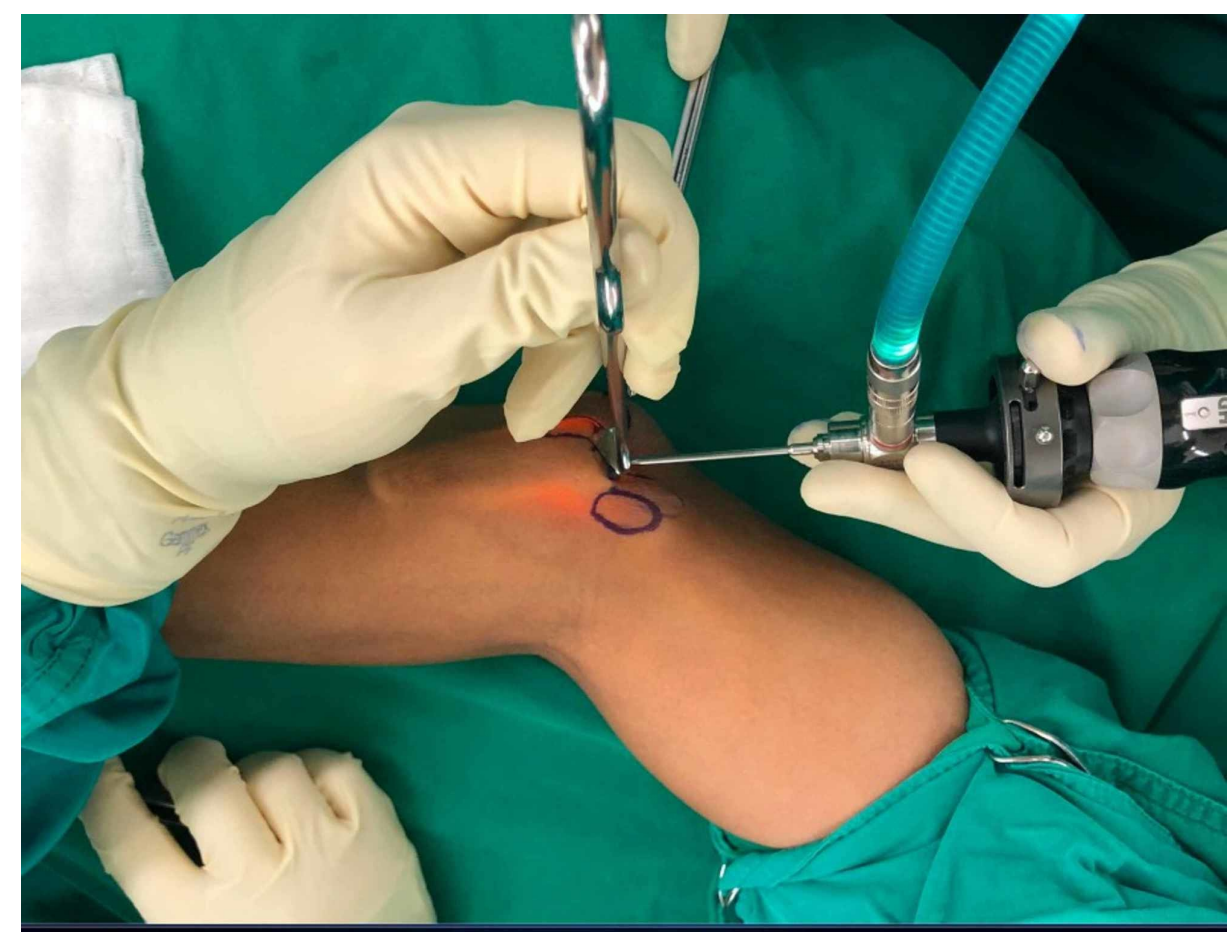

FIGURE 2: The $2.5 \mathrm{~mm}$ endoscope is utilized to illuminate and magnify the surgical area

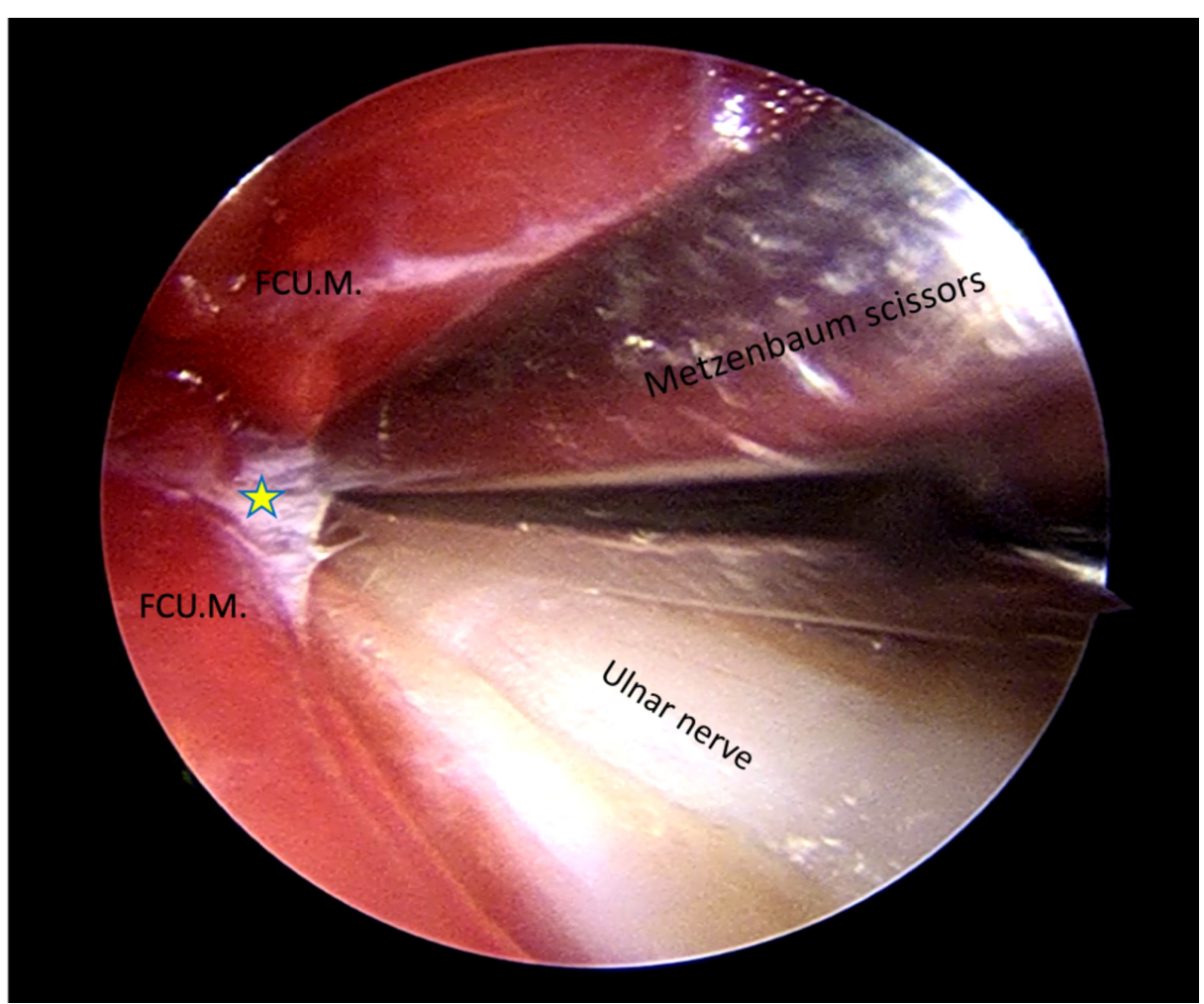

FIGURE 3: Endoscopic view: a narrow Metzenbaum scissors is introduced to dissect the fascia between the two heads of the flexor carpi ulnaris muscle

FCU.M.: Flexor carpi ulnaris muscle; star: facia between the two heads of the flexor carpi ulnaris muscle 


\section{Results}

There were nine patients with CuTS, including five males and four females, with an average age of 49 years. One patient presented with Grade 1 severity according to the McGowan classification. four presented with Grade 2a, and the other four with Grade $2 \mathrm{~b}$ (Table 3). Postoperative follow-up of the first 10 days was performed by a telephonic questionnaire and the wound was evaluated by photos through e-mail. There was no complication-related surgery in all nine patients, such as for infection, new or different paresthesia, periincisional numbness, hematomas, or dehiscence. There was no ulnar nerve subluxation prior to and after the operation. The length of the surgical incision was 7-9 mm. The visual analog score shows that on the first day after surgery, six patients reported a scale of 1 , two patients reported 2 , and one patient experienced a scale of 3 (Table 4). All patients had no pain in the second week postoperation. Only two patients needed rest because of concern for their wound healing but not the pain while the others were able to return to work one day after the operation. Modified Bishop score showed an excellent result for four patients in the first week, three good results, and two fair (Table 5). In three months, the results were five excellence and four good. In six months, all patients reported an excellent result. All patients reported excellent satisfaction both in the first week and the sixth month, which they would undergo the same operation again given the opportunity.

\begin{tabular}{|c|c|c|c|c|c|}
\hline Patient & Sex & Age & Diagnosis & Modified McGowan score & Duration of symptoms (months) \\
\hline No.1 & $\mathrm{F}$ & 48 & Rt. CuTS & $2 \mathrm{~b}$ & 10 \\
\hline No.2 & $M$ & 59 & Lt. CuTS & $2 a$ & 9.5 \\
\hline No.3 & $\mathrm{F}$ & 54 & Lt. CuTS & $2 a$ & 22 \\
\hline No.4 & $M$ & 47 & Rt. CuTS & $2 b$ & 8 \\
\hline No.5 & $\mathrm{M}$ & 50 & Rt. CuTS & $2 \mathrm{~b}$ & 12 \\
\hline No.6 & $F$ & 52 & Rt. CuTS & $2 a$ & 13.4 \\
\hline No.7 & M & 42 & Rt. CuTS & $2 a$ & 27 \\
\hline No.8 & $\mathrm{M}$ & 46 & Lt. CuTS & $2 b$ & 7 \\
\hline No.9 & $\mathrm{F}$ & 41 & Rt. CuTS & 1 & 6 \\
\hline
\end{tabular}

TABLE 3: Demographic data

\begin{tabular}{|c|c|c|c|c|c|c|c|c|c|c|c|c|c|c|c|}
\hline \multicolumn{16}{|c|}{ Postoperative pain score (VAS) } \\
\hline \multirow[t]{2}{*}{ Patient } & \multicolumn{10}{|c|}{ Day(s) } & \multicolumn{3}{|c|}{ Week(s) } & \multicolumn{2}{|c|}{ Month(s) } \\
\hline & 1 & 2 & 3 & 4 & 5 & 6 & 7 & 8 & 9 & 10 & 2 & 4 & 6 & 3 & 6 \\
\hline No.1 & 1 & 1 & 1 & 1 & 1 & 0 & 1 & 0 & 1 & 0 & 0 & 0 & 0 & 0 & 0 \\
\hline No.2 & 1 & 1 & 1 & 1 & 1 & 1 & 1 & 1 & 1 & 0 & 0 & 0 & 0 & 0 & 0 \\
\hline No.3 & 1 & 2 & 1 & 1 & 1 & 1 & 2 & 1 & 0 & 0 & 0 & 0 & 0 & 0 & 0 \\
\hline No.4 & 1 & 1 & 1 & 1 & 1 & 1 & 0 & 0 & 0 & 0 & 0 & 0 & 0 & 0 & 0 \\
\hline No.5 & 2 & 1 & 1 & 1 & 1 & 2 & 1 & 1 & 1 & 0 & 0 & 0 & 0 & 0 & 0 \\
\hline No.6 & 1 & 1 & 1 & 1 & 1 & 1 & 1 & 1 & 0 & 0 & 0 & 0 & 0 & 0 & 0 \\
\hline No.7 & 1 & 1 & 1 & 1 & 1 & 1 & 0 & 0 & 0 & 0 & 0 & 0 & 0 & 0 & 0 \\
\hline No.8 & 1 & 2 & 1 & 1 & 1 & 1 & 1 & 1 & 1 & 0 & 0 & 0 & 0 & 0 & 0 \\
\hline No.9 & 3 & 2 & 1 & 1 & 0 & 0 & 0 & 0 & 0 & 0 & 0 & 0 & 0 & 0 & 0 \\
\hline
\end{tabular}

TABLE 4: Postoperative pain score 


\section{Cureus}

\begin{tabular}{|c|c|c|c|c|}
\hline \multicolumn{5}{|c|}{ Modified Bishop score } \\
\hline \multirow[t]{2}{*}{ Patient } & \multicolumn{2}{|c|}{ Week(s) } & \multicolumn{2}{|c|}{ Month(s) } \\
\hline & 1 & 2 & 3 & 6 \\
\hline No.1 & 7 & 7 & 7 & 7 \\
\hline No.2 & 8 & 8 & 8 & 8 \\
\hline No.3 & 5 & 6 & 6 & 7 \\
\hline No.4 & 8 & 8 & 8 & 8 \\
\hline No.5 & 7 & 8 & 8 & 8 \\
\hline No.6 & 7 & 7 & 7 & 7 \\
\hline No.7 & 5 & 6 & 6 & 7 \\
\hline No.8 & 8 & 8 & 8 & 8 \\
\hline No.9 & 8 & 8 & 8 & 9 \\
\hline
\end{tabular}

TABLE 5: Postoperative modified Bishop score

\section{Discussion}

In situ decompression of the ulnar nerve has steadily gained support from many studies for its effectiveness and low complication rate [3]. Historically, open cubital tunnel release has been the standard procedure for most surgeons. There were many common complications, such as peri-incisional pain or numbness, wound dehiscence, hematomas, or iatrogenic nerve injury, reported. These complications could be related to the large incision required [6]. Recently, minimally invasive procedures, such as the minimal incision and endoscopic techniques, have become more favorable, with the theoretical benefits of a smaller incision, reduced pain and time of return to work, and iatrogenic injury to nerve branches, vessels, and surrounding tissue [12]. With the technique that this study proposed, the incision needed was $7-9 \mathrm{~mm}$, which is considered almost half that in the minimal incisional technique $[6,13]$. But it still has the benefit of the endoscope maintaining clear visualization along the decompression side. All the patients reported a pain score of 1 out of 10 only on Day 3 and were completely pain-free after Day 10. Seven of nine patients could return to work after one day of surgery. The others refused to go back to work because of concern for their wound healing but not the pain. These results may contribute to the smaller incision as compared to previous studies. There were two patients who relatively have fair results from the modified Bishop score, which may be caused by the duration of symptoms before surgery.

The limitations of this study are its retrospective manner and small sample size.

\section{Conclusions}

This study purposed the minimal incision endoscopic in situ ulnar nerve decompression technique as being cost-effective, with favorable outcomes, without the use of special instruments, and easily replicable. A large prospective trial may be useful for further evaluation of the technique.

\section{Additional Information \\ Disclosures}

Human subjects: Consent was obtained by all participants in this study. Police General Hospital ethics committee issued approval 0036(20)/477. The Police General Hospital ethics committee approve of the study "Cost-saving minimal incision endoscopic-assisted cubital tunnel release using simple surgical instruments: Case series" according to Pol.Sub-Lt.Dr. Woraphon Jaroenporn proposed. Conflicts of interest: In compliance with the ICMJE uniform disclosure form, all authors declare the following: Payment/services info: All authors have declared that no financial support was received from any organization for the submitted work. Financial relationships: All authors have declared that they have no financial relationships at present or within the previous three years with any organizations that might have an interest in the submitted work. Other relationships: All authors have declared that there are no other relationships or activities that could appear to have influenced the submitted work.

\section{References}


1. Lauretti L, D'Alessandris QG, De Simone C, Legninda Sop FY, Remore LM, Izzo A, Fernandez E: Ulnar nerve entrapment at the elbow. A surgical series and a systematic review of the literature. J Clin Neurosci. 2017, 46:99-108. 10.1016/j.jocn.2017.08.012

2. Nathan PA, Istvan JA, Meadows KD: Intermediate and long-term outcome following simple decompression of the ulnar nerve at the elbow. Chir Main. 2005 Feb, 24:29-34.

3. Malay S, Chung KC: The minimal clinically important difference after simple decompression for ulnar neuropathy at the elbow. J Hand Surg Am. 2013, 38:652-659. 10.1016/j.jhsa.2013.01.022

4. Watts AC, Bain GI: Patient-rated outcome of ulnar nerve decompression: comparison of endoscopic and open in situ decompression. J Hand Surg Am. 2009, 34:1492-1498. 10.1016/i.jhsa.2009.05.014

5. Dützmann S, Martin KD, Sobottka S, Marquardt G, Schackert G, Seifert V, Krishnan KG: Open vs retractorendoscopic in situ decompression of the ulnar nerve in cubital tunnel syndrome: a retrospective cohort study. Neurosurgery. 2013, 72:605-616. 10.1227/NEU.0b013e3182846dbd

6. Rashid G, Tora MS, Di L, Texakalidis P, Bentley JN, Boulis NM: Case series: a minimally invasive tunneling approach for cubital tunnel syndrome. Cureus. 2019, 25:4540.

7. Mirza A, Mirza JB, Lee BK, Adhya S, Litwa J, Lorenzana DJ: An anatomical basis for endoscopic cubital tunnel release and associated clinical outcomes. J Hand Surg Am. 2014, 39:1363-1369. 10.1016/j.jhsa.2014.04.030

8. Said J, Frizzell K, Heimur J, Kachooei A, Beredjiklian P, Rivlin M: Visualization during endoscopic versus open cubital tunnel decompression: a cadaveric study. J Hand Surg Am. 2019, 44:697-601. 10.1016/j.jhsa.2018.10.004

9. Law TY, Hubbard ZS, Chieng LO, Chim HW: Trends in open and endoscopic cubital tunnel release in the Medicare patient population. Hand (N Y). 2017 Jul, 12:408-412. 10.1177/1558944716679610

10. Goldberg BJ, Light TR, Blair SJ: Ulnar neuropathy at the elbow: results of medial epicondylectomy . J Hand Surg Am. 1989, 14:182-188.

11. Kleinman WB, Bishop AT: Anterior intramuscular transposition of the ulnar nerve. J Hand Surg Am. 1989, 14:972-978.

12. Hoffmann R, Lubahn J: Endoscopic cubital tunnel release using the Hoffmann technique . J Hand Surg Am. 2013, 38:1234-1239. 10.1016/j.jhsa.2013.03.043

13. Taniguchi Y, Takami M, Takami T, Yoshida M: Simple decompression with small skin incision for cubital tunnel syndrome. J Hand Surg Br. 2002, 27:559-562. 10.1054/jhsb.2002.0821 